\title{
Težave pri prevajanju svetniških imen
}

\author{
SIMONA ŠTAVBAR \\ Univerza v Mariboru, Filozofska fakulteta, Koroška cesta 160, \\ SI-2000 Maribor,simonastavbar@gmail.com
}

SCN VIII/1 [2015], 135-146

\begin{abstract}
Prispevek želi osvetliti prevajanje svetniških imen in njim posvečenih cerkva in poimenovanj umetniških upodobitev iz slovenščine $\mathrm{v}$ angleščino in nemščino. Opisano je prevajanje imen in navedene so posebnosti tega. Na podlagi očitnejših in pogostejših napak (pomenskih in slovničnih) v izbranih vodnikih, priročnikih in na spletu so podane prevodne rešitve za svetniška imena in nekatera regionalna poimenovanja njim posvečenih cerkva in umetniških upodobitev $\mathrm{v}$ angleščini in nemščini. Zaradi kompleksnosti tematike je potrebno poudariti pomen védenja, opozoriti je treba na natančnost in doslednost pri prevajanju ter spodbuditi $\mathrm{k}$ nadaljnjim raziskavam.
\end{abstract}

The topic of this article is translation of saints' names from Slovenian into German and English, and of churches and artistic works dedicated to saints. The translation of saints' names and specific features of names are described. Translation options are suggested for names and certain regional names of churches and artistic works dedicated to saints in English and German. They are based on the frequent and evident errors (semantic and grammatical) found in selected guides, reference works, and on the Internet. Due to the complexity of this topic, it is necessary to stress the importance of knowledge and the consistency necessary for this kind of translation, and to encourage further research.

Ključne besede: svetniška imena, prevajanje, napake, predlog prevodnih rešitev

Key words: saints' names, translation, errors, suggested translation options

\section{Prevajanje svetniških imen ${ }^{1}$}

Prevajanje svetniških imen iz slovenščine $\mathrm{v}$ angleščino in nemščino se zdi zaradi večkrat enakih prevodnih ustreznic v zapisu, npr. slv. sv. Barbara, nem.

\footnotetext{
${ }^{1}$ Prispevek je bil predstavljen na simpoziju Pleteršnikovi dnevi, 9. 9. 2013, in je predstavitev dela Svetniška imena in njihovo prevajanje (Štavbar 2013).
} 
hl. Barbara, angl. St. Barbara, dokaj preprosto. Vendar pa lahko zaradi številnih poimenovanj za svetnike in lokalnih variant njihovih imen, predvsem pa zaradi najrazličnejših uradnih in številnih lokalnih poimenovanj svetnikom posvečenih cerkva doma in $\mathrm{v}$ tujini in poimenovanj umetniških del vidimo, da težav ne povzroča zgolj prevajanje imena, temveč tudi prevajanje prilastka ob imenu, besedni red v strukturi poimenovanja, pogosto pa tudi prevajanje celotne imenske zveze $\mathrm{v}$ povezavi z občnim imenom.

V prevedenih priročnikih in vodnikih o Sloveniji v knjižni obliki, besedilih na spletu, napisih na objektih, predvsem cerkvah in kapelah, v strokovnih besedilih in podnapisih umetniških del ugotovimo, da prihaja pri prevajanju poimenovanj za svetnike in njim posvečenih cerkva in umetniških upodobitev $\mathrm{v}$ nemščino in angleščino do neustreznih prevodnih ustreznic. Veliko teh je $\mathrm{v}$ besedilih na spletu, kjer je skrb za ustrezen oziroma dober prevod večkrat drugotnega pomena, manj pa v vodnikih in strokovnih publikacijah, kjer poleg prevajalcev in lektorjev pogosto sodelujejo še področni strokovnjaki. V prispevku bo zato obravnavano prevajanje svetniških imen in težave v povezavi s tem, navedena in komentirana bodo najpogostejša napačno prevedena svetniška imena iz slovenščine $\mathrm{v}$ angleščino in nemščino, opozorjeno bo na kolokacijsko združljivost oz. nezdružljivost nekaterih poimenovanj v angleščini in nemščini, ustaljeno rabo, ponujene pa bodo tudi prevodne rešitve.

\section{Razlogi za prevajanje svetniških imen}

Svetniška imena, ki so se in se še širijo prek prevodov hagiografij in drugih del o svetnikih, molitvenih obrazcev, pridig, poimenovanj cerkva, objektov idr. so del mednarodne cerkvene in kulturne dediščine. Ker v raznih jezikih najdemo različne ustreznice svetniških imen, to pomeni, da se imena prevajajo. To navaja tudi Klinar, ki glede prevajanja svetniških imen trdi: Ime za samega svetnika (in druge verske reči) in ime za cerkev pa se vedno prevaja. (1994: 59) V tem kontekstu se svetniška imena razlikujejo od osebnih lastnih imen, ki jih običajno ne prevajamo. ${ }^{2}$ Slovenski pravopis namreč navaja, da osebnih imen običajno ne prevajamo, razen če gre za pravljična bitja in vzdevke (SP 2001: § 181).

Reindl trdi, da lahko svetniška imena vzporejamo s kategorijami imen, kot so npr. pravljična bitja, literarni junaki, zgodovinske osebe, ki so v različnih jezikih različna (2007: 1):

\footnotetext{
${ }^{2}$ Grahova navaja, da je osebna imena, predvsem pa rojstna imena v določenih okoliščinah možno prevajati, in sicer po navadi takrat, kadar se uporabljajo v obmejnih območjih ali pri prestopu v drugo jezikovno kulturo (Drago/Charles/Karl) (2002: 23). Prevajanje imen (vse tja do preimenovanja) je pogosto tudi v okoljih, kjer prihaja do tesnejšega kulturnega, gospodarskega, predvsem pa političnega stika oz. močnejšega vplivanja ene družbe na drugo, prim. npr. slv. Franc Kavčič $\rightarrow$ nem. Franz Caucig.
} 


\begin{tabular}{|c|c|c|c|}
\hline Kategorija & Slovensko & Angleško & Nemško \\
\hline • papež & - Janez Pavel II & - John Paul II & - Johannes Paul II. \\
\hline • kralj & • Jurij VI. & • George VI & • Georg VI. \\
\hline • cesar & - Karel Veliki & - Charlemagne & - Karl der Große \\
\hline - pravljični lik & • Pepelka & - Cinderella & • Aschenputtel \\
\hline • lik v stripu & - stric Skopušnik & - Scrooge McDuck & • Onkel Dagobert \\
\hline - literarni junak & - Pika Nogavička & - Pippy Longstocking & - Pippi Langstrumpf \\
\hline
\end{tabular}

Slika 1: Tabela kategorij imen

Iz navedenega lahko sklepamo, da svetniška imena prevajamo podobno kot druga iz seznama, saj spadajo k spominskim imenom. Iz razpredelnice je razvidno, da so pomenski premiki pri poimenovanju prisotni predvsem tam, kjer so imena bolj domišljijsko motivirana, metaforična (npr. slov. stric Skopušnik in angl. Scrooge McDuck). Iz navedenih primerov lahko sklepamo tudi na to, prek katerega jezika se je ime preneslo v drug jezik (npr. slov. Pepelka iz nem. Aschenputtel), seveda pa lahko tudi ugotovimo, da so imena v jezikih enakega izvora pogosto podobna (prim. nem. Georg VI. in angl. George VI). Podobno bi lahko ugotovili za svetniška imena, saj so tista imena, ki so po izvoru starejša, enodelna ali metaforična ter manj spominjajo na osebna lastna imena, pogosteje povsem prevedljiva (podomačena) ${ }^{3}$ in $\mathrm{v}$ prevodu $\mathrm{v}$ različnih jezikih drugačna od tistih imen, ki so po obliki podobna osebnim lastnim imenom, npr. $s v$. Jošt $\rightarrow$ St. Jodoc, hl. Jodok in sv. Kateri Tekakwitha $\rightarrow$ St. Kateri Tekakwitha, hl. Kateri Tekakwitha. Medtem ko slednja pogosto ohranjajo izvirno podobo, imajo prva običajno tudi več variant imena: sv. Jošt $\rightarrow$ St. Jodoc, Jodocus, Josse, Jost; hl. Jodok, Jodokus, Jost, Jobst. ${ }^{4}$ Pri svetnikih pogosto tudi opazimo, da lahko imajo poleg imena še vzdevek, enega ali več, ki kaže na odnos verujočega do svete osebe, ki je v povezavi s kako značilnostjo svetnika in ki se tudi prevaja. ${ }^{5}$

\section{Iskanje prevodnih ustreznic}

Iskanje prevodnih ustreznic in prevajanje imen si lahko nekoliko olajšamo tako, da imena razdelimo v naslednje tri skupine:

\footnotetext{
${ }^{3} \mathrm{~V}$ podomačeni obliki pa poleg 1. Plavt/us/ pišemo še 2. imena vladarskih in plemiških rodovin, 3. znanih zgodovinskih oseb, 4. svetnikov, 5. nekatera prevzeta imena in priimke in 6. imena narodov in prebivalcev. Vsa druga načeloma ohranijo izvirno podobo (SP 2001: § 171-179).

${ }^{4}$ Pri tem velja opozoriti na zanimivo prenašanje prilastka starejši/mlajši z osebnega imena na svetniško ime, kjer pa to, npr. v angleščini, ni mogoče prevajati s Sen./Jr., temveč je ustaljeno Great/Less (prim. poglavje 7.1).

${ }^{5}$ Npr. vzdevek svetnice $s v$. Kateri Tekakwitha je v nem. Lilie der Mohawks in v angl. Lily of the Mohawks.
} 
- svetniška imena $\mathrm{v}$ slovenščini so $\mathrm{v}$ pisavi popolnoma identična prevodnim ustreznicam v angleščini oz. nemščini: Peter, Barbara, Abraham, Adalbert, Afra, Martin, Benjamin, Bernard;

- nekoliko drugačna: Marta (angl. Martha, nem. Martha), Janez (angl. John, nem. Johannes), Matija (angl. Matthias, nem. Matthias);

- povsem drugačna:

a) regionalna oz. ljudska imenska oblika: Areh (angl. Henry, nem. Heinrich), Bolfenk (angl. Wolfgang, nem. Wolfgang), Urh (angl. Ulric, nem. Ulrich), Jera (angl. Gertrude, nem. Gertrud);

b) imena, oblikovana pod različnimi vplivi: Jernej (angl. Bartholomew, nem. Bartholomäus);

c) posebnost imena: starozavezni Jakob je v angleščini Jacob, medtem ko so ostali Jakobi v angleščini James (Klinar 1994: 10).

Pri primerih, kot so Areh (a), je v primerih ljudskih oblik imena najprej potrebno ugotoviti, katero ime je izhodiščno. Pri tem so nam v pomoč zgodovinski in drugi viri ter etimologija. V primeru sv. Areha na podlagi virov sklepamo, da gre za hagionim Henrik. ${ }^{6}$ Urh je nastal iz nemške oblike imena Ulrich. V primeru slovenske oblike imena Jernej, ki jo uvrščamo v drugo skupino (b), pa gre za mešanje romanskih in germanskih vplivov. ${ }^{7}$ Veliko ugibanj lahko povzročijo tudi enobesedni hagionimi sv. Anton, sv. Gertruda, sv. Elizabeta idr. Ta imena so v Sloveniji zelo pogosta, a je dobro, da preverimo, za katerega sv. Antona, katero sv. Elizabeto in katero sv. Gertrudo gre. Svetnikov, ki imajo podobno osebno ime, temu pa sledi različen lastnoimenski stalni pridevek, je več. V primeru sv. Antona so to lahko naslednji svetniki: sv. Anton (Veliki) (nem. hl. Antonius (der Große), angl. St. Anthony), sv. Anton Marija Claret (nem. hl. Antonius Maria Claret, angl. St. Anthony Mary Claret), sv. Anton Marija Zaccaria (nem. hl. Antonius Maria Zaccaria, angl. St. Anthony Mary Zaccaria), Sv. Anton Padovanski (nem. hl. Antonius von Padua, angl. St. Anthony of Padua) idr. V Sloveniji se sv. Anton pogosto nanaša na sv. Antona Padovanskega, ${ }^{8}$ a je možno, da gre tudi za katerega drugega Antona. Podobno velja za $s v$. Gertrudo, ki se pojavlja v slovenski imenski obliki sv. Jera. Tudi pri sv. Jeri imamo dve svetnici z istim imenom: sv. Jedrt (nem. hl. Gertrud (von Nivelles), angl. St. Gertrude (of Nivelles) in sv. Jedrt iz Helfte (nem. hl. Gertrud von Helfta, angl. St. Gertrude of Helfta). Ustreznega svetnika lahko najdemo v Letu svetnikov (Smolik 1999-2001), primerjamo slovenski in angleški oz. nemški koledar cerkvenega leta ali pa prevodne ustreznice imen preverimo na

\footnotetext{
${ }^{6}$ V nekaterih krajih na Štajerskem (območje Pohorja) so imeli velik vpliv, zaradi posestev in župnij, ki so jim pripadale, šentpavelski benediktinci s Koroškega. Ti menihi so na svojem ozemlju zelo širili češčenje sv. Henrika.

${ }^{7}$ Premk po Bezlaju navaja, da je Jernej nastal s prepletanjem romanskih in germanskih vplivov, in sicer z mešanjem Bartholomäus in Irenäus (Premk 2004: 120).

${ }^{8}$ Sv. Antona Padovanskega so Slovenci na zahodu države poznali, ker naj bi se leta 1229 mudil v Guminu. Njegovo ime je pri nas izjemno priljubljeno (Merkù 1992: 11).
} 
spletu (npr. na spletnih straneh: http://www.heiligenlexikon.de in http://www. catholic.org/saints/). V pomoč nam je lahko npr. tudi slovar svetniških imen v angleščini, The Oxford Dictionary of Saints (Farmer 2004). Pri prevajanju v tuj jezik, kadar imamo le del imena, kot npr. sv. Anton, torej brez desnega lastnoimenskega stalnega pridevka Padovanski, v prevodu tega ni potrebno dodati. Dovolj je, da prevedemo del imena, ki je naveden, torej St. Anthony $\mathrm{v}$ angleščini in $h l$. Antonius v nemščini. Lahko pa v oklepaju pojasnjevalno navedemo še lastnoimenski stalni pridevek, če domnevamo, da bi lahko prišlo do zamenjave.

\section{Imenske različice, pokrajinske in druge variante svetniških imen}

Pri svetniških imenih pogosto opazimo več različic imena, ki se zdijo sinonimne. ${ }^{9}$ Od teh je običajno ena tista, ki se najpogosteje uporablja in je ustaljena, ostale pa se uporabljajo v določenih kontekstih. Zato moramo preveriti, katera varianta imena se običajno uporablja in ali je ustaljena. Sv. Anton (Veliki) ima v angleščini več možnih variant: Anthony the Abbot, Anthony of Egypt, Desert Father. Možne sopomenske variante imena $s v$. Jošt so v nemščini poleg $h l$. Jodok še: Jodokus, Jodocus, Jost, Jobst in v angleščini: St. Jodoc, Judoc, Josse, Jodocus, Jost, Joyce. Tudi glede na to, katera varianta je ustreznejša glede na besedilno vrsto, kontekst in okoliščine ter Cerkev, ${ }^{10}$ je treba poiskati in navajati ustrezno obliko imena.

Pri poimenovanjih cerkvenih objektov, kot so cerkve, kapelice, znamenja ipd., naletimo tudi na naslednja imena: $s v$. Sobota, sv. Genderca, sv. Socerb, sv. Elio (iz Koštabone), sv. Bolfenk (tudi Volbenk, Štoblenk), sv. Gera, sv. Jelar (Volar), sv. Lekš, sv. Areh, bl. Liharda, sv. Kuma (Kümmernis), sv. Židor, sv. Jungrt, sv. Kurin, sv. K(v)irik, sv. Onofrij, sv. Basso, sv. Ilj, sv. Jerolim, Šentomprga (sv. Valburga), Šempolaj (sv. Pelagij), sv. Jungert (sv. Kunigunda), sv. Jeruf ... Pogosto so te variante dialektalna ali ljudska svetniška imena, kot lahko ugotovimo v primeru sv. Gertrude, ki je lahko sv. Jera, sv. Gera, sv. Jedert, sv. Jedrt ali celo sv. Genderca. Kadar so taka imena prevedljiva, kot je npr. $s v$. Areh, jih prevedemo, v nasprotnem primeru pa je bolje, da neprevedljivo obliko imena pustimo v izvirniku, pojasnjevalno frazo pa damo v navednice ali jo navedemo v oklepaju: sv. Genderca (a local name for St. Gertrude; regionaler Name für hl. Gertrud). Reindl navaja, da lahko dialektalno obliko v določenih primerih primerjamo z vzdevkom in jo kot vzdevek tudi prevedemo v angleščino: St. Joe's za St. Joseph in St. Tony's za St. Anthony (2007: 3) ter St. Nick's za St. Nicholas, St. Pat's za St. Patrick in St. Al's za St. Alphonsus. Te oblike uporabljamo predvsem za doseganje stilističnega učinka $v$ določenih

\footnotetext{
${ }^{9}$ Imenske variante so se oblikovale tudi kot posledica (so)vplivanja različnih jezikov, prim. npr. sv. Jošt.

${ }^{10}$ Ezekijel je v Nemčiji v Katoliški cerkvi poimenovan Ezechiel, v Evangeličanski cerkvi pa Hesekiel (prim. http://www.heiligenlexikon.de/BiographienE/Ezechiel.html).
} 
kontekstih in okoliščinah, ki so predvsem pragmatični, v strokovna besedila pa jih ne vključujemo.

\section{Svetniška imena $v$ paru}

Svetniška imena v parih najpogosteje zasledimo pri poimenovanju stvarnih lastnih imen, kot so imena ulic in trgov, društev, cerkva (kot zavetnikov cerkva) in župnij. Ta so sv. Mohor in Fortunat, sv. Peter in Pavel, sv. Ciril in Metod, sv. Simon in Juda Tadej, sv. Primož in Felicijan, sv. Kozma in Damijan, sv. Gervazij in Protazij, sv. Krispin in Krispinijan, sv. Hilarij in Tacijan, sv. Filip in Jakob in druga. ${ }^{11}$ Ta poimenovanja so ustaljena po obliki in rabi, saj med imeni ni inverzije tipa $s v$. Metod in Ciril. Pri prevajanju teh imen je potrebno to upoštevati in prevesti obe imenski sestavini, ker se v slovenskem prostoru uporabljata obe in opuščanje katere od sestavin v prevodu ni možno. V nasprotju s tem pri navajanju imen v povezavi s poimenovanji cerkva v ZDA lahko opazimo težnjo po navajanju zgolj imena prvega svetnika v paru, npr. sv. Ciril, opušča pa se navajanje drugega, tj. sv. Metod, čeprav je cerkev uradno poimenovana po obeh. ${ }^{12}$

Hagionimi v paru se lahko tvorijo tudi priložnostno in taka imena niso ustaljena glede kombinacije obeh imen, npr. cerkev sv. Justa in Evfemije. Podobne kombinacije neustaljenih oblik najdemo tudi drugod. Tako je ena od župnij v Detroitu, ZDA, poimenovana SS. Andrew and Benedict Parish. To je razlog, da moramo zmeraj preveriti, v kakšnem vrstnem redu si imena sledijo, ker lahko $\mathrm{v}$ nasprotnem primeru pride do napačnega prevoda.

\section{Prilastek sveti in njegova raba}

Ob imenih svetnikov v slovenščini navajamo prilastek sveti. Za vse ostale svete osebe namesto prilastka sveti uporabimo drug ustaljen pridevek, ki je v povezavi z osebo, npr. prerok Daniel, kraljica Ester, očak Abraham itn. V nemščini je ustreznica za sveti heilig, velikokrat pa naletimo tudi na ustreznico Sankt, ki je nastala pod vplivom latinskega sanctus. V besednih zvezah sta obe varianti običajno okrajšani: St. ali hl./hll. St. se zmeraj zapisuje z veliko začetnico, hl./hll. pa z malo, razen če je sestavni del imena (Kloster Heiligenblut, Stift Heiligenkreuz). Množina je pri $h l$. nakazana s podvojenim $l$ (Kirche der hll. Rochus und Sebastian), St. pa ostane v množini nespremenjen. Pri prevajanju imen cerkva uporabljamo St. z ničtim členom, zvezo cerkev/kapela ... + hl./ hll. + ime svetnika pa z določnim členom. Ta ima vlogo desnega rodilniškega

${ }^{11} \mathrm{~V}$ imenih ulic in trgov: Ciril-Metodov trg; imenih društev: Ciril-Metodovo društvo; cerkev sv. Primoža in Felicijana v Vrhpolju.

${ }^{12} \mathrm{Npr}$. v primeru imena cerkve sv. Cirila in Metoda: /.../ ceremony to be performed at St. Cyril's. (vir: http://stcyril.org/?p=3620). 
prilastka (Kirche des hl. Lorenz). Kot del zloženke se pri prevajanju imen cerkva uporablja okrajšava St. (St.-Emmeram-Kirche). V nasprotju s slovenščino, kjer je raba prilastka sveti zelo pogosta, pa ta predvsem na severu Nemčije peša (Markuskirche, Peterskirche) (Grah 2002: 13). ${ }^{13}$ Svojilna oblika tipa Markova cerkev, Petrova cerkev v slovenščini ni običajna. Sugerira lastnika objekta, torej svojino, ne pa po svetniku poimenovan oz. njemu posvečen cerkveni objekt. V angleščini imajo prilastek sveti z redkimi izjemami samo novozavezni svetniki. Vse ostale svete osebe imajo druge prilastke, pogosto v povezavi z vlogo ali položajem, ki ga opravljajo oz. imajo: Abraham (the Patriarch), Balthazar (the Magus), Daniel (the Prophet), (Pope) Damasus I, King David, Esther (Queen of Persia), Gabriel (the Archangel) ... Reindl tudi ugotavlja, da prilastka sveti $\mathrm{v}$ angleščini ne moremo uporabljati v primerih, ko ne gre za svete osebe (2007: 4). V takih primerih uporabljamo prilastke Holy, Blessed, Divine, Sacred idr., ki pa niso poljubno izmenljivi, temveč sledijo ustaljeni rabi. V tem kontekstu je izjema tudi Marija, ki v angleščini z nekaterimi izjemami ni Holy Mary, temveč Virgin Mary, v povezavi z umetniškimi upodobitvami Madonna in v poimenovanjih cerkva zelo pogosto Our Lady of / .../.14

\section{Težave pri prevajanju svetniških imen}

Pri pregledu besedil o Sloveniji v knjižni obliki in na spletu ter turističnih vodnikov in besedil $\mathrm{v}$ tiskani obliki kot tudi naslovov umetniških del ugotovimo pomenske in slovnične napake. Teh je precej v besedilih na spletu, kjer je skrb za ustrezen prevod pogosto pomanjkljiva, manj pa $v$ tiskanih besedilih. Primere napačno prevedenih imen najdemo tudi v vodnikih, ki so jih napisali nemški in angleški materni govorci. Prevajalci pogosto kljub Klinarjevemu (1994: 59) priporočilu glede prevajanja svetniških imen teh občasno niso prevedli $\mathrm{v}$ angleščino ali pa so ta napačno prevedena. V nadaljevanju so zato najprej navedeni neustrezni prevodi svetniških imen $\mathrm{v}$ angleščino, nato v nemščino. Ti so komentirani, ponujene so tudi prevodne ustreznice.

\subsection{Neustrezne prevodne rešitve pri prevajanju svetniških imen $v$ angleščino}

a) Napačno navajanje prilastka sveti:

Prilastek sveti $\mathrm{v}$ naslednjem primeru ni ustrezno okrajšan oz. je v angleščino prevzeta italijanska prevodna ustreznica:

- chapel of S. Rocco - ustrezno: St. Roch (Kovačič idr. 2012: 92)

${ }^{13}$ Opuščanje prilastka sveti sicer zasledimo tudi drugod po Nemčiji. V pretežni meri gre za evangeličanske cerkve, npr. Markuskirche v Ludwigshafnu ali Peterskirche v Leipzigu.

${ }^{14}$ Zelo pogosto uporabljena zveza, npr. v poimenovanjih naslednjih cerkva: Our Lady of Lourdes, Our Lady of the Woods, Our Lady of the Lake, Our Lady of the Snows, Our Lady of Mt. Carmel itd. 
b) Prilastek St. in neprevedeno slovensko ime:

Pogostejša napaka, ki jo najdemo v vodnikih in besedilih na spletu je preveden prilastek in neprevedeno svetniško ime. Do tega prihaja velikokrat tam, kjer gre za lokalno varianto imena, ki jo prevajalci obravnavajo kot neprevedljivo slovensko obliko svetniškega imena in jo ohranijo v izvirni obliki. Med taka imena se zagotovo lahko uvrsti sv. Areha, sv. Bolfenka, sv. Urha, sv. Jošta, sv. Kunigundo in druga podobna imena.

- [neo-Romanesque church of] St. Urh-ustrezno: St. Ulric (Fallon 2004: 130)

- Saints Rok, [Fabian and Sebastian] - ustrezno: Saints Roch, [Fabian and Sebastian] (Fallon 2004: 98)

- [the old church of] St. Rok - ustrezno: St. Roch (Natek 1998: 72)

- [the 18th-century chapel in the shaft is dedicated to St. Barbara and] St. Ahacustrezno: St. Acacius (Fallon 2004: 141)

- [the parish church of] St. Stefan - ustrezno: St. Stephen (Natek 1998: 95)

- [the parish church of] St. Kunigunda - ustrezno: St. Cunegund (Curk 2000: 161)

- [gothic church of] St. Bolfenk - ustrezno: St. Wolfgang (Curk 2000: 165)

- [succursal church of] St. Areh ${ }^{15}$ - ustrezno: St. Henry (Curk 2000: 165)

- [church of] St. Ambrož - ustrezno: St. Ambrose (Kovačič idr. 2012: 84)

- [church of] St. Andrej - ustrezno: St. Andrew (Kovačič idr. 2012: 88)

- [Sv. Jernej] (St. Jernej) - ustrezno: St. Bartholomew (Pivka 2012: 130)

- St. Kvirik - ustrezno: St. Cyricus (tudi Quiriac) (Bradeško 2009: 7)

- St. Mohor and Fortunat [cathedral] - ustrezno: Sts. Hermagoras and Fortunatus (Bradeško 2009: 55)

- St. Jošt [church] - ustrezno: St. Jodoc (Bradeško 2009: 67)

c) Napačno preveden prilastek starejši:

Osebnim lastnim imenom se včasih dodaja desni prilastek starejši ali mlajši, vendar prevodne ustreznice starejši ali mlajši z osebnih lastnih imen ne moremo prenesti na svetniška imena. Prevodne ustreznice so v naslednjem primeru Great oz. Less. ${ }^{16}$

- [the parish Church of] St. James, Snr - ustrezno: St. James the Great (tudi St. James the Greater) ${ }^{17}$ (Curk 2000: 108) $^{18}$

15 tako succursal church kot tudi branch church (branch church of St. Silvester (Kovačič idr. 2012: 90) se ne rabita za poimenovanje podružnične cerkve. Ustreznejše bi navedeno lahko prevedli kot affiliate church. Podobno poimenovanje poznamo v nemščini, in sicer Filialkirche.

${ }^{16}$ Relacijsko razmerje kot sestavina imena je pri poimenovanju svetnikov redko izraženo. Prisotno je npr. v poimenovanju $s v$. Ane, in sicer v umetniških upodobitvah: $s v$. Ana Samotretja, nem. hl. Anna Selbdritt. V angleškem prostoru v tem primeru prevajajo kot frazo: Virgin and Child with St. Anne.

${ }^{17}$ St. James v poimenovanju cerkve v St. Louisu v ZDA: St. James the Greater Catholic Church. Varianti Greater in Lesser sta sicer manj pogosti, Oxford Dictionary of Saints (Farmer 2004) jih na primer ne navaja.

${ }^{18}$ St. James, Sr. (Sv. Jakob St.) je še druga podobna varianta (Narodna galerija). 
d) Neustrezno prevedeno ime:

Pogosto so neustrezne prevodne ustreznice posledica nekoliko drugačnega zapisa svetniškega imena v ciljnem jeziku. Zaradi podobne izgovarjave, a drugačnega zapisa svetniškega imena $\mathrm{v}$ prevodu povzroči napake.

- [around] St. Chaterine [monastery] - ustrezno: St. Catherine (Adria Airways In-Flight Magazine 2010: 32)

- [the parish church of] St. Kancian - ustrezno: St. Cantianus (Natek 1998: 82)

- [the sarcophagus of] St. Nazarus - ustrezno: St. Nazarius (Natek 1998: 83)

- [altar of] St. Roche - ustrezno: St. Roch (Curk 2000: 114)

\subsection{Neustrezne prevodne rešitve pri prevajanju svetniških imen $v$ nemščino}

Pri prevajanju v nemščino so napake pogosto podobnega tipa. Največkrat gre za pomenske napake, ko je svetniško ime neustrezno prevedeno, ko to ni prevedeno ali pa ostane neprevedena celotna poimenovalna struktura. Pogosta slovnična napaka je v primerih, ko levi prilastek $h l$. ni v ustreznem sklonu. Pogost je tudi napačen besedni red $v$ strukturi poimenovanja.

a) Prilastek $h l$. in neprevedeno svetniško ime:

Podobno kot pri prevajanju v angleščino tudi tu svetniško ime ostane neprevedeno. Tudi tukaj prevajalci ime, ki ga obravnavajo kot neprevedljivo slovensko obliko svetniškega imena, ohranijo v izvirni obliki. Tudi v tem primeru gre za sv. Roka.

- [Kapelle des] hl. Rok-ustrezno: [Kapelle des] hl. Rochus (Kovačič idr. 2012: 93)

b) Prilastek $h l$. in napačno prevedeno ime:

Napačen prevod imena je posledica neustrezne oblike imena. Ustrezna slovenska oblika pa je navedena v oklepaju. Primer je zanimiv, ker je prevajalec naravni govorec nemščine.

- [Kirche des] hl. Bas (Cerkev Sv. Basso) - ustrezno: [die Kirche des] hl. Bassus (Schulze 2004: 104)

c) Napačno preveden prilastek starejši:

Pri svetniških imenih kot prevodno ustreznico za prilastek starejši ne navajamo sen., temveč v primeru nemških svetniških imen navajamo der Ältere ali der Jüngere.

- [Pfarrkirche des] hl. Jakob sen. - ustrezno: [die Pfarrkirche] St. Jakobus der Ältere (Curk 2000: 108)

d) Prilastek $h l$. ni preveden, tudi svetniško ime ne: 
V primeru dialektalnih imenskih oblik tudi v nemščini ta velikokrat ostajajo neprevedena. Med slednjimi najpogosteje $s v$. Areh, sv. Bolfenk, sv. Kunigunda ipd.

- Hl. Bolfenk [auf dem Pohorje-Gebirge] - ustrezno: hl. Wolfgang /.../ (Maribor - Pohorje Tourist Board 2013)

e) Napačen besedni red v povezavi s poimenovanjem:

Napačna struktura poimenovanja je posledica napačnega besednega reda $\mathrm{v}$ strukturi. Spodnji primeri bi bili ustrezni, če bi namesto prilastka $h l$. prevajalec uporabil prilastek $S t$. Prilastek $h l$. namreč zahteva naslednje: ime objekta $+d o-$ ločni člen v genitivu $+h l$. + svetniško ime. Enako velja tudi, ko imamo poleg napačne strukture neprevedeno tudi svetniško ime (f).

- /.../ mit der hl. Peter Kirche - ustrezno: /.../ mit der Kirche des hl. Peter (Kovačič idr. 2012: 73)

- die hl. Michael Filialkirche - ustrezno: mit der Filialkirche des hl. Michael (Kovačič idr. 2012: 81)

f) V naslednjih primerih poleg napačnega besednega reda oz. sklona tudi svetniško ime ni prevedeno:

- die kleine hl. Ambrož Kirche - ustrezno: die kleine Kirche des hl. Ambrosius (Kovačič idr. 2012: 85)

- neben der Kirche hl. Andrej-ustrezno: neben der Kirche des hl. Andreas (Kovačič idr. 2012: 89)

\section{VIRI IN LITERATURA}

Adria Airways, 2010: Adria Airways In-Flight Magazine. Http://issuu.com/akersnic/ docs/adria_airways_inflight_oct_nov_2010: 32 (pridobljeno 3. septembra 2013).

Marjan BRADEŠKO, 2009: Privlačna Slovenija = Slovenia attacts. Ljubljana: Kmečki glas.

Catholic Online, 2008: Catholic Online Saints\&Angels. Http://www.catholic.org (pridobljeno 5. septembra 2013).

Jože CURK, 2000: Maribor: a guide to the town and its vicinity. Maribor: Primož Premzl Art Cabinet.

Cyril \& Methodius Parish, 2014: http://www.stcyril.org/?p=3620 (pridobljeno 5. septembra 2013).

Stephen FALLON, 2004: Slovenia. Hawthorn: Lonely Planet Publications.

David Hugh FARMER, 2004: The Oxford Dictionary of Saints. New York: Oxford University Press.

Käthe GRAH, 2002: Slovenska stvarna imena v nemških besedilih. Slowenische Sachnamen in deutschen Texten. Ljubljana: Znanstveni inštitut Filozofske fakultete. 
Stanko KLINAR, 1994: Slovenska zemljepisna imena v angleških besedilih. Radovljica: Didakta.

Simon KOVAČIČ, Igor MAHER, Andrej BANDELJ, Barbara JEJČIČ, 2012: Zgodovinske poti med Krasom in Sočo = Itinerari storici tra Carso e Isonzo = Historical routes between Carst and Isonzo = Historische Wege zwischen Karst und Isonzo. Kranj: Gorenjski tisk.

Maribor - Pohorje Tourist Board, 2013: http://maribor-pohorje.si/Zentrum-f\%C3\%BCr-Natur--und-Kulturerbe-Bolfenk-auf-dem-Pohorje-Gebirge.aspx (pridobljeno 5. septembra 2013).

Pavle MERKÙ, 1992: Svetniki v slovenskem imenoslovju. Trst: Mladika.

Narodna galerija. Http://www.ng-slo.si/si/ (pridobljeno 5. septembra 2013).

Karel NATEK, 1998: Discover Slovenia. Ljubljana: Cankarjeva založba.

Jurij PIVKA, 2012: Maribor - mesto navdiha $=$ Maribor - city of inspiration. Miklavž na Dravskem polju: Roman.

Francka PREMK, 2004: Slovenska versko-krščanska terminologija v zemljepisnih imenih in spremembe za čas 1921-1967/1968. Besedoslovne lastnosti slovenskega jezika: slovenska zemljepisna imena. Pišece, Društvo Pleteršnikova domačija, 12. in 13. september 2003. Ur. Marko Jesenšek. Ljubljana: Slavistično društvo Slovenije. 113-132.

Donald REINDL, 2007: Slovenian Sacral Onomastics: Anglicization and Other Linguistic Observations. Ljubljana, Filozofska fakulteta. Predavanje v okviru Lingvističnega krožka Filozofske fakultete (3. december 2007).

Joachim SCHÄFER, 2010: Ökumenisches Heiligenlexikon. Http://www.heiligenlexikon. de (pridobljeno 5. septembra 2013).

Dieter SCHULZE, 2004: Slowenien. Köln: DuMont.

Marjan SMOLIK (ur.), 1999-2001: Leto svetnikov. 2. prenovljena in razširjena izdaja. 5 zv. Celje: Mohorjeva družba.

Simona ŠTAVBAR, 2013: Svetniška imena in njihovo prevajanje. Maribor: Mednarodna založba Oddelka za slovanske jezike in književnosti, Filozofska fakulteta. (Mednarodna knjižna zbirka Zora, 98).

The Catholic Directory.com., 2000-2014: https://www.thecatholicdirectory.com/ (pridobljeno 5. septembra 2013).

Jože TOPORIŠIČ, 2001: Slovenski pravopis. Ljubljana: Založba ZRC, ZRC SAZU.

\section{DIFFICULTIES IN TRANSLATION OF SAINTS’ NAMES}

The topic of this article is the translation of saints' names from Slovene into German and English. It aims to show that the translation of saints' names refers to and includes a wide social and linguistic context. Therefore, this article emphasizes the social and interlinguistic transfer that played a decisive role in the formation and frequency of saints' 
names in Slovenia. The usage of these names is not restricted to a certain geographical area; therefore, it is necessary to stress the importance of the naming policy.

Saints' names are considered a part of the international cultural heritage and are thus translated. This article provides several reasons why saints' names are translated; describes how and where to find translation equivalents for saints' names in Slovene, German and English; examines various saints' names that function as synonyms; examines pairs of saints' names and their placement in the naming pattern; looks at several regional as well as dialectal variants of saints' names; and describes the use of the attribute 'saint' as well as other attributes in Slovene, German and English. It further examines the current translation solutions regarding names in selected tourist guides, reference books, and on the Internet and suggests more accurate translation options for equivalents of saints' names in English and German. These are formed on the basis of types of errors (semantic and grammatical) found in the aforementioned texts. As for English, the following types of errors can be observed: saints' names are not translated accurately; the attribute $\mathrm{Sr} . / \mathrm{Snr}$. [starejši] is applied instead of the attribute Great; only the attribute St. is translated and not the name; the attribute St. is not rendered correctly. In German, the most frequent errors are similar to those in English: the name is not translated; the name is not rendered correctly; the attribute der Ältere should be applied instead of sen. [starejši]; the word order in the name pattern is not correct and the name of the saint is not translated.

Therefore, it is necessary to stress the importance of the knowledge the translator has to obtain when translating saints' names, to point out the consistency necessary in this kind of translation, and to encourage further research. 